\title{
Reagent Free Light-Driven Site Selective Carbon-Carbon Coupling of Aliphatic Alcohols with 1,4-Naphthoquinones
}

\author{
Raushan Kumar Jha, Aditya Upadhyay, Kanika, Saket Jain, Neena KA and Sangit Kumar* \\ Supporting Information Placeholder
}

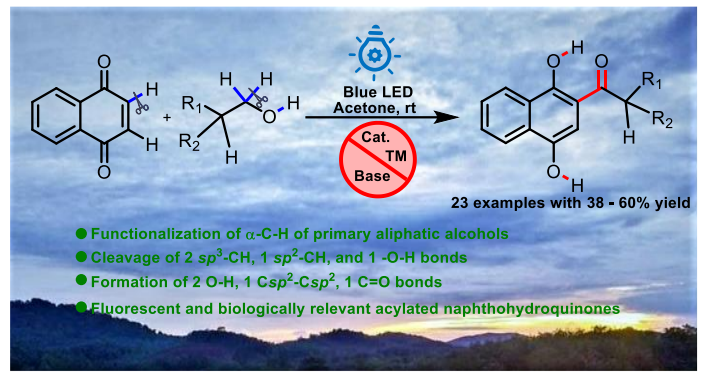

ABSTRACT: Here, first-ever an $\alpha$-selective $\mathrm{C}_{s p 3}-\mathrm{H}$ bond functionalization of primary aliphatic alcohols with 1,4-naphthoquinones yielded $\mathrm{C}_{s p 2}-\mathrm{C}_{s p 2}$ coupled products is reported, driven by blue-LEDs light in photo-catalyst, metal, base, reagent free conditions. In this transformation, cleavage of three $\mathrm{C}-\mathrm{H}$ bonds (two $s p^{3}-\mathrm{C}-\mathrm{H}$, one $s p^{2}-\mathrm{C}-\mathrm{H}$, and one $\mathrm{O}-\mathrm{H}$ ) and four new bonds formed, leading to fluorescent 2-acylated-1,4-naphthohydroquinones.

Quinones are widespread in bacteria, plants, and even in the human body. ${ }^{1}$ Naphthoquinones are essential members of the quinone family. They can generate reactive oxygen species such as superoxides $\left(\mathrm{O}_{2}^{--}\right)$and hydroxyl radicals ${ }^{2}\left(\mathrm{HO}^{\circ}\right)$ and strongly induce cancer cell death by oxidizing DNA base pairs or/and lipids. $^{3}$ Substituted 2-acylated-1,4-naphthohydroquinones also show good cytotoxicity towards various cancer cells. ${ }^{3 \mathrm{~b}}$ Naphthoquinones serve as valuable and multifaceted precursors for constructing biologically active natural products, such as Elutherin, Isoetherin, Deoxyfrenolicin, and Frenolicin (Chart 1). ${ }^{4}$ Furthermore acylated quinones serve as useful key intermediates for pharmaceutically active molecules, such as Shikonin, Alkannin, and Deoxyshikonin. ${ }^{5}$

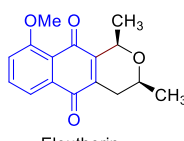

Eleutherin

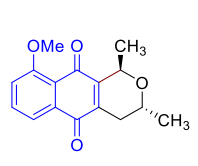

Isoeleutherin (Anticancer Drug)
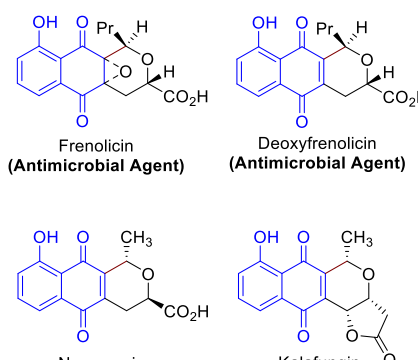

Nanomycin
(Antimicrobial Agent)

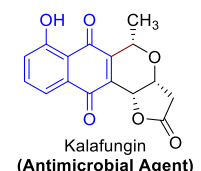

Antimicrobial Agent)

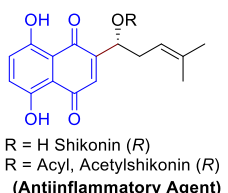
(Antiinflammatory Agent)

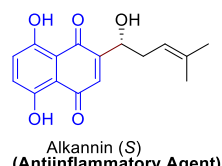

Chart 1. Various pyranonaphthoquinones with acylated quinone cores

Aliphatic alcohols are widely available and are mainly used for $\mathrm{C}-\mathrm{O}$ coupling reactions. Coupling of the $s p^{3}-\mathrm{C}-\mathrm{H}$ bond over $-\mathrm{O}-$ $\mathrm{H}$ and often the site-selective functionalization of non-activated aliphatic alcohols are attractive yet, bit challenging. ${ }^{6}$ Many strategies have been developed for functionalizing the $s p^{3}-\mathrm{C}-\mathrm{H}$ bond of alcohols selectively; however, halogenating reagents or transition metals are required to activate the $\mathrm{C}-\mathrm{H}$ bonds. ${ }^{7}$

Further, the direct formation of carbon-carbon bonds by the coupling of $s p^{2}-\mathrm{C}-\mathrm{H}$ and $s p^{3}-\mathrm{C}-\mathrm{H}$ is an attractive area, ${ }^{8}$ particularly in the presence of $\mathrm{O}-\mathrm{H},-\mathrm{CO}_{2} \mathrm{H}, \mathrm{NH}_{2}$ functional groups as preferential $\mathrm{C}-\mathrm{C}$ coupling has to be achieved over favourable $\mathrm{C}$ $\mathrm{O} / \mathrm{N}$ heteroatom coupling reaction. In recent times, research has shifted towards the execution of light-induced greener protocols for constructing carbon-carbon and carbon-heteroatom bonds. ${ }^{9-}$ ${ }^{10}$ Lei and co-workers have used photocatalysts for various photoredox transformations in organic synthesis, namely acetalization of aldehydes with alcohols, ${ }^{9 f}$ oxidant-free oxidative $\mathrm{C}$ $\mathrm{H} / \mathrm{N}-\mathrm{H}$ cross-coupling between arenes and azoles, ${ }^{\text {gh }}$ and oxidative activation of $\alpha-\mathrm{C}-\mathrm{H}$ bond of alcohol. ${ }^{\mathrm{k}}$ Also König and coworkers developed cooperative asymmetric organophotoredox catalysis for intermolecular $\alpha$-alkylation of aldehydes, ${ }^{10 a}$ and metal-free methods using photocatalyst for direct $\mathrm{C}-\mathrm{H}$ arylation of heteroarenes with aryl diazonium salts, ${ }^{10 \mathrm{c}}$ and photocarboxylation of benzylic $\mathrm{C}-\mathrm{H}$ bonds. ${ }^{10 \mathrm{e}}$

Earlier light-mediated synthesis of 2-acylated-1,4-naphthohydroquinone have been reported from 1,4-naphthoquinone and aldehyde using benzene, fluorinated solvent, ionic liquid (Scheme 1). ${ }^{11}$

Scheme 1. Photo acylation of naphthoquinones 


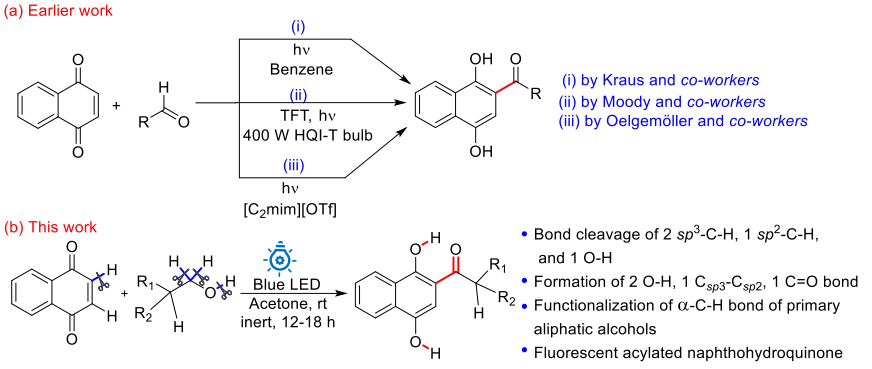

Recently our group has studied the anticancer activity of the some organoselenium compounds. ${ }^{12}$ Next, we envisioned constructing naphthoquinones (potent ROS generator) ${ }^{13}$ substituted organoselenium from diaryl diselenide and naphthoquinones. Serendipitously, coupling of the $s p^{3}-\mathrm{C}-\mathrm{H}$ bond of ethanol solvent with the $s p^{2}-\mathrm{C}-\mathrm{H}$ bond of naphthoquinone was realized in the reaction. Here in continuation of our work on $\mathrm{C}-\mathrm{C}$ coupling, ${ }^{8 c, 8 e}$ particularly light-induced coupling reactions, ${ }^{9 \mathrm{~g}, 10 \mathrm{f}}$ we report the site-selective functionalization of the $s p^{3}-\mathrm{C}-\mathrm{H}$ bond of primary aliphatic alcohols with the $\mathrm{sp}^{2}-\mathrm{C}-\mathrm{H}$ bond of naphthoquinone for the synthesis of fluorescent $\mathrm{C}_{s p 2}-\mathrm{C}_{s p 2}$ coupled 2acylated-1,4-naphthphydroquinones under blue light irradiation.

For the optimization of the reaction condition, 4-phenyl-1-butanol was chosen as a primary aliphatic alcohol (to monitor the other side product easily) along with 1,4-naphthoquinone in various solvents under the blue light irradiation (for blue light irradiation, a household setup box was fabricated using blue LED strips of 240 watts, for setup, See SI, page S3).

Table 1. Optimization of reaction conditions.

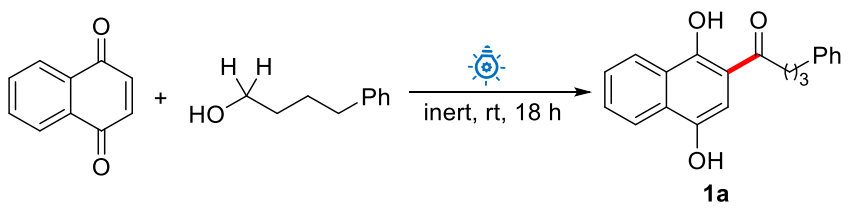

$\begin{array}{ccc}\text { Entry } & \text { Solvent / Additive / Catalyst } & \text { Yield }^{a}(\%) \\ 1 & \text { Trifluorotoluene } & 15 \\ 2 & \text { Benzene } & 18 \\ 3 & \mathrm{CH}_{2} \mathrm{Cl}_{2} & 22 \\ 4 & \mathrm{THF} & 23 \\ 5 & \mathrm{EtOAc} & 30 \\ 6 & \mathrm{CH}_{3} \mathrm{CN} & 48 \\ 7 & \text { Acetone } & \mathbf{6 0} \\ 8 & \text { Acetone / Eosin Y } & 10 \\ 9 & \text { Acetone / BQ } & \text { trace } \\ 10 & \text { Acetone / PQ } & \text { trace } \\ 11 & \text { Acetone / Benzophenone } & \text { trace } \\ 12^{b} & \text { Acetone } & \text { NR } \\ 13^{c} & \text { Acetone } & 20\end{array}$

The reactions were carried out using $1.26 \mathrm{mmol}$ of naphthoquinone and $2.52 \mathrm{mmol}$ of alcohol in $5 \mathrm{~mL}$ of solvent at room temperature under an inert atmosphere in a household fabricated blue-LEDs box for $18 \mathrm{~h}$. ${ }^{\text {a }}$ Percentage isolated yield. ${ }^{\mathrm{b}}$ Reaction was carried out in the dark. ${ }^{c}$ Reaction was carried out in sunlight for 3 days. The optimal reaction condition was highlighted in bold.
Various solvents were screened under the reaction conditions (entries 1-7) at room temperature. When triflourotoluene, benzene, $\mathrm{CH}_{2} \mathrm{Cl}_{2}$, THF, and ethyl acetate solvents were tested (Table 1 , entries 1-5), the desired $s p^{2}-\mathrm{C}-\mathrm{H}$ and $s p^{2}-\mathrm{C}-\mathrm{H}$ coupled product 1a was obtained with 15, 18, 22, 23, and 30\% yields, respectively. When the reaction was performed in $\mathrm{CH}_{3} \mathrm{CN}$ and acetone, a noticeable increase of $12 \%$ in the yield of the desired product 1a was observed (Table 1, entries 6-7). Acetone was found to be superior, and a $60 \%$ yield of 1a was observed (Table 1, entry 7). This reaction was also performed in a UV reactor (mercury vapor lamp, 450 watts); nonetheless, nearly the same yield of 1a was realized ( $62 \% v s .60 \%$ using blue-LED light). Next, photo-catalysts (20 mol \%), namely Eosin Y, benzoquinone (BQ), phenanthrene-9,10-dione (PQ), and benzophenone were explored under the light irradiation conditions, less or no formation $s p^{2}-\mathrm{CH}$ and $s p^{2}-\mathrm{CH}$ coupled product 1a was observed, disappointingly, (Table 1, Entry 8-11). The reaction was performed in the dark using the optimized conditions (entry 7); no desired product $1 \mathbf{a}$ was perceived (Table 1, entry 12). Moreover, the optimized reaction was also performed under sunlight, which provided less yield (10\%) under similar time $(18 \mathrm{~h})$, and a longer duration ( 3 days) is needed to obtain $\mathrm{C}-\mathrm{C}$ coupled product $\mathbf{1 a}$ in $20 \%$ yield (Table 1, entry 13 ).

After screening of the conditions, the substrate scope with respect to various aliphatic alcohols was explored. As shown in Scheme 2, a variety of simple aliphatic ethanol to $n$-decanol underwent $\mathrm{C}_{s p 2}-\mathrm{C}_{s p 2}$ coupling to afford respective 2-acylated-1,4naphthohydroquinones $\mathbf{1 b}-\mathbf{1 j}$ in $54-58 \%$ yields as crystalline solids. The structures $\mathbf{1 d}$ and $\mathbf{1 e}$ are also studied by single-crystal XRD. After exploring the normal straight-chain aliphatic alcohols, $2^{\circ}$ (isopropanol and phenyl-2-ethanol) and $3^{\circ}\left({ }^{t} \mathrm{BuOH}\right)$ alcohols were tested under the blue-LEDs irradiation, $\mathrm{C}-\mathrm{C}$ coupling of isopropanol, 2-phenylethanol and tert-butanol with naphthoquinone could not be realized which suggest that the two $\alpha-\mathrm{C}-\mathrm{H}$ bonds are necessary to get $\mathrm{C}-\mathrm{C}$ coupled product. Next, $\beta$-substituted 2-methylpropan-1-ol, 2-methylpentan-1-ol and 2-ethylhexan-1-ol alcohols were also successfully coupled with 1,4-naphthoquinone to afford respective $\mathbf{1 k}, \mathbf{1 m}$, and $\mathbf{1 0}$ in Scheme 2. Blue light driven site selective functionalization of $\alpha-\mathrm{C}-\mathrm{H}$ of primary aliphatic alcohols with 1,4-Naphthoquinone
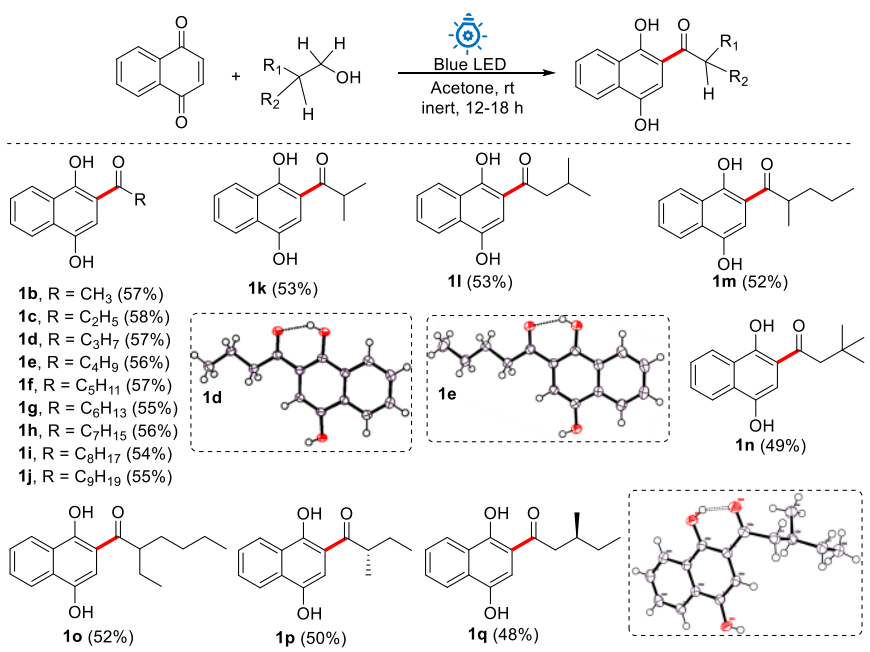

$52-53 \%$ yields under the optimized blue-LED irradiated condition. Encouraged by the coupling of $\beta$-substituted 2 -methylpropan-1-ol, 2-methylpentan-1-ol and 2-ethylhexan-1-ol alcohols, 
chiral $\beta$-substituted (S)-(-)-2-Methyl-1-butanol was explored, coupled product $1 \mathbf{p}$ was obtained with retention of the chirality. $\gamma$-Substituted alcohols also successfully coupled provided the desired C-C coupled acylated naphthoquinones 11, 1n, and chiral (S)-1-(1,4-dihydroxynaphthalen-2-yl)-3-methylpentan-1one (1q). Single-crystal XRD of 1q reveals that it crystallized in orthorhombic P $2{ }_{1}{ }_{1} 2_{1}$ chiral space group with Flack parameter 0.2 , which is close to zero and suggestive of enantiomeric purity of the sample.

The reaction of benzyl alcohol with naphthoquinone was noticed to be sluggish and afforded a complex reaction mixture. The reaction of $\mathrm{CH}_{3} \mathrm{OH}$ with naphthoquinone seems to enable 1,4-dihydroxy-2-naphthaldehyde, however, it reacted further with methanol leading to functionalization of all three $s p^{3}-\mathrm{C}-\mathrm{H}$ bonds of methanol to afford the methyl ester 2 in $45 \%$ yield (Scheme 3).

Scheme 3. The reaction between 1,4-Naphthoquinone and methanol in blue LEDs light. Structure of 2 is established by single $\mathrm{X}$-ray crystal structure

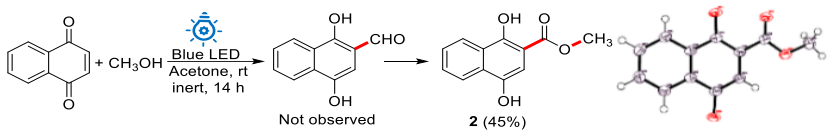

Next, diols were explored, the reaction of ethylene glycol failed to give desired C-C coupled product (Scheme 4 ). The reaction of 1,3-propanediol, 1,4-butanediol, 1,5-pentanediol, 1,6-hexanediol, and 1,7-heptanediol give desired $\mathrm{C}_{s p 2}-\mathrm{C}_{s p 2}$ coupled products $3 \mathrm{a}-3 \mathrm{e}$ in $37-43 \%$ yields, respectively. Mono-functionalized naphthoquinone $3 \mathrm{~d}$ is studied by single-crystal XRD. Interestingly, $\alpha-\mathrm{C}-\mathrm{H}$ bonds of only $\mathrm{OH}$ functionality reacted with naphthoquinone, and $\alpha-\mathrm{C}-\mathrm{H}$ bonds of second $\mathrm{OH}$ didn't react further with naphthoquinone either intramolecularly or intermolecularly.

Scheme 4. Blue light-driven mono-selective functionalization of $\alpha-\mathrm{C}-\mathrm{H}$ of primary aliphatic diols with 1,4-naphthoquinone

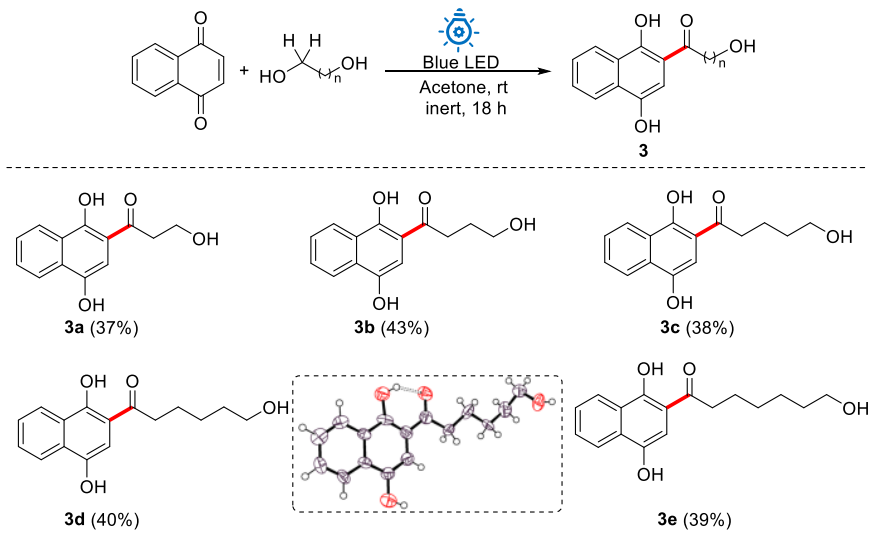

${ }^{1} \mathrm{H}$ NMR of synthesized alcohol coupled naphthoquinones 1a3e showed a characteristic peak at $\delta>13$ ppm for hydroxy group (sharp singlets, locked in an intramolecular $-\mathrm{C}=\mathrm{O}$...H-O- hydrogen bond) and second -OH shows at 4.5-5.5 ppm (brs). The synthesized 2-acylated-1,4-naphthohydroquinones 1a-3e are fluorescent and shows emission spectra in the range of 516-525 $\mathrm{nm}$ and absorption in the range of 382-397 nm (ESI, page S22S110).

Scheme 5. Control experiments for mechanistic study
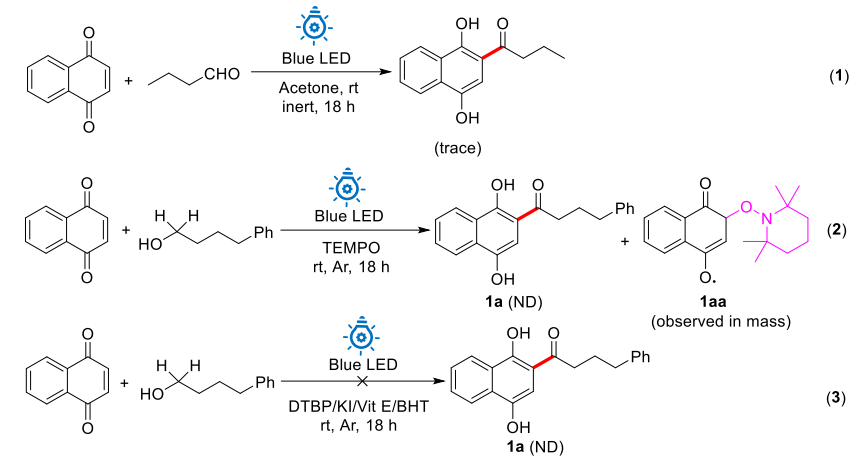

In the mechanistic understanding, we suspected that alcohol might be oxidized to an aldehyde under the reaction conditions, and then could lead to C-C coupled acylated naphthoquinones as reported earlier by Moody et al., ${ }^{11 a}$ Oelgemöller et al. ${ }^{11 \mathrm{i},}$ and Kraus et al. ${ }^{11 \mathrm{j}-11 \mathrm{~K}}$ The reaction of butanal with naphthoquinone was studied under the optimized reaction condition, which afforded only a trace of C-C coupled product 1d (eq 1, Scheme $5)$. Next, several alcohols namely $n$-prop-, $n$-but-, $n$-pent-, isobutanols, which used here as coupling partners has been analysed by GC to observe if any respective aldehydes are present. The GC analysis of the alcohols do not indicate the presence of the respective aldehyde. This suggests that the alcohols are indeed the coupling partner with naphthoquinone under the bluelight irradiated conditions.

As in the reaction, two hydrogen atoms were rearranged, two hydrogen atoms were removed, and the reaction was conducted under oxidant free conditions. GC-TCD analysis of the gas involved (if any) during the course of the reaction, does not show any change in the concentration of the gases, particularly, hydrogen gas evolved from reaction was not observed, which suggests the coupling of $s p^{2}-\mathrm{C}-\mathrm{H}$ bond of naphthoquinone with $s p^{3}$ $\mathrm{C}-\mathrm{H}$ bonds of alcohol does not proceed dehydrogenative pathway.

Further, a reaction in the presence of a radical quencher TEMPO shows the formation of TEMPO-quinone adduct 1aa as observed in mass spectrometry [observed $\mathrm{m} / \mathrm{z}(\mathrm{M}+\mathrm{H})^{+}=$ 315.1829, calcd. 315.1834]. Next, the reaction was performed in the presence of radical scavengers: 2,6-di-tert-butylphenol (DTBP), vitamin E, KI, and 2,6-di-tert-butyl-4-methylphenol (BHT), the formation of the desired 2-acylated-1,4-naphthohydroquinone 1a was also not observed (eq 3, Scheme 5).

Further, blue-LEDs light irradiated reaction mixture of naphthoquinone and 4-phenyl-1-butanol was monitored by EPR at various time intervals (Figure 1). The reaction mixture in $\mathrm{CH}_{3} \mathrm{CN}$ under dark conditions was noticed to be EPR silent (a, Figure 1).

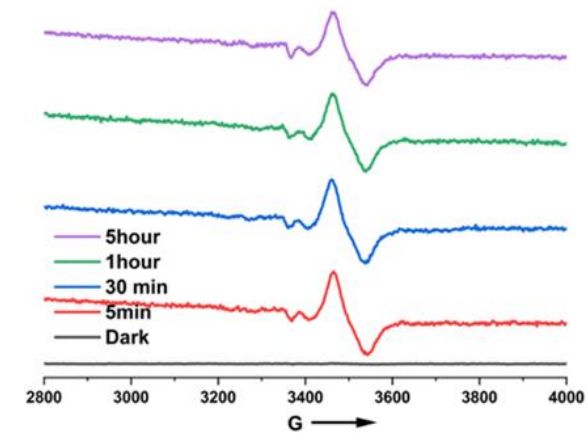

Figure 1. EPR spectra of the reaction mixture at different time intervals 
Upon Blue LEDs light irradiation, the reaction mixture shows a singlet with g value of 1.94 (Figure 1). The second-and thirdtime irradiation of the same reaction mixture again showed a singlet signal in the EPR spectrum, suggesting that the continuous irradiation of the reaction mixture is necessary to achieve the maximum conversion.

In this mechanistic pathway (Scheme 6), irradiation of naphthoquinone yields triplet excited state biradical I. ${ }^{14}$ Which abstract hydrogen of $\alpha-\mathrm{C}-\mathrm{H}$ bond of the alcohol (because of weak $\mathrm{BDE}^{14 \mathrm{c}}$ around $100 \mathrm{kcal} / \mathrm{mol}$ ) forming a radical pair $\mathbf{\text { II. }}{ }^{14 \mathrm{~b}}$ Then carbon centred radical in quinone of II would rearrange to radical pair III. Subsequent, radical-radical cross-coupling shall provide 4-hydroxy-2-(1-hydroxyalkyl)naphthalen-1(2H)-one IV, which undergo hydrogen atom transfer to biradical I, forming the oxygen centred radicals VA and VI. Then intramolecular 1,5-HAT and hydrogen abstraction by VA would furnish desired alcohol coupled 2-acylatednaphtho1,4-hydroquinone $\mathbf{1}$ and naphthalene-1,4-diol VII which converted back naphthoquinone upon the oxidation. ${ }^{14 \mathrm{~d}}$ Naphthalene-1,4-diol VII could not be isolated from the reaction mixture, however, confirmed by ${ }^{1} \mathrm{H}$ NMR study of the reaction mixture, conducted in an NMR tube using $\mathrm{CD}_{3} \mathrm{CN}$.

Scheme 6. A plausible mechanism of the $\mathrm{C}-\mathrm{C}$ coupling reaction between 1,4-naphthoquinones and aliphatic alcohols

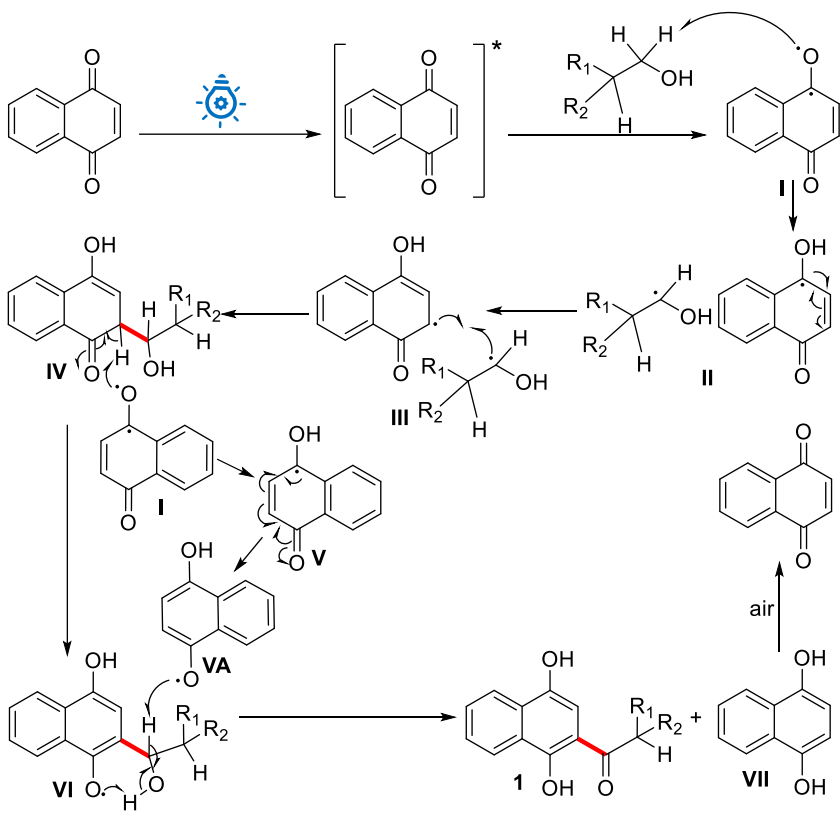

In summary, we have unravelled a blue light mediated coupling of $s p^{3}-\mathrm{CH}$ bond of alcohols selectively with naphthoquinones under reagents, base, metal free conditions for the synthesis of biologically important fluorescent 2-acylated-1,4-naphthohydroquoinones. The green process, good yields and low costs chemicals can be utilized for synthesizing precursor for biologically and pharmaceutically active molecules. Currently, efforts are being made to transform readily available alcohols into fine chemicals under light irradiated conditions.

\section{ASSOCIATED CONTENT}

\section{Supporting Information}

The Supporting Information is available free of charge on the ACS Publications website.

Experimental details, characterization data, and ${ }^{1} \mathrm{H}$ and

${ }^{13} \mathrm{C}$ NMR spectra (PDF)

\section{Accession Codes}

CCDC 2117979-80, and 2141611-13 contains the supplementary crystallographic data for this paper. These data can be obtained free of charge via www.ccdc.cam.ac.uk/data_request/cif, or by emailing data_request@ccdc.cam.ac.uk, or by contacting The Cambridge Crystallographic Data Centre, 12 Union Road, Cambridge CB2 1EZ, UK; fax: +44 1223336033.

\section{AUTHOR INFORMATION}

\section{Corresponding Author}

Sangit Kumar - Department of Chemistry, Indian Institute of Science Education and Research (IISER) Bhopal, Indore By-pass Road, Bhauri, Bhopal, Madhya Pradesh, India-462 066; Email: sangitkumar@iiserb.ac.in

\section{Authors}

Raushan Kumar Jha - Department of Chemistry, Indian Institute of Science Education and Research (IISER) Bhopal, Indore Bypass Road, Bhauri, Bhopal, Madhya Pradesh, India-462 066

Aditya Upadhyay - Department of Chemistry, Indian Institute of Science Education and Research (IISER) Bhopal, Indore By-pass Road, Bhauri, Bhopal, Madhya Pradesh, India-462 066

Kanika - Department of Chemistry, Indian Institute of Science Education and Research (IISER) Bhopal, Indore By-pass Road, Bhauri, Bhopal, Madhya Pradesh, India-462 066

Saket Jain - Department of Chemistry, Indian Institute of Science Education and Research (IISER) Bhopal, Indore By-pass Road, Bhauri, Bhopal, Madhya Pradesh, India-462 066

Neena KA - Department of Chemistry, Indian Institute of Science Education and Research (IISER) Bhopal, Indore By-pass Road, Bhauri, Bhopal, Madhya Pradesh, India-462 066

\section{Author Contributions}

SK and RJ designed the research. RJ, KK, NKA synthesized all 2acylated-1,4-naphthohydroquinone. The crystal structure studies carried out by R. J. All other spectroscopic techniques were done by RJ, SJ and AU. RJ and SK wrote the manuscript.

Notes

There is no conflict of interests.

\section{ACKNOWLEDGMENT}

This work is financed by IISER Bhopal and SERB (SERB/CHM/2019049) New Delhi.

\section{REFERENCES}

1 R. H. Thomson, "Naturally Occurring Quinones IV," Springer, 1997.

2 (a) T. Ohnishi, H. Yamazaki, T. Iyanagi, T. Nakamura, and I. Yamazaki, Biochim. Biophys. Acta-Bioenerg., 1969, 172, 357; (b) C. Lind, P. Hochstein, and L. Ernster, Arch. Biochem. Biophys., 1982, 216, 178.

3 (a) D. Siegel, P. Reigan, and D. Ross, "In Advances in Bioactivation Research," Elfarra, A. Ed.; Springer: New York, Vol. IX, p 1, 2008; (b) D. A. Pedroza, F. D. Leon, A. VarelaRamirez, C. Lema, R. J. Aguilera, and S. Mito, Bioorg. Med. Chem., 2014, 22, 842-847; (c) M. Dufour, C. Yan, D. Siegel, M. A. Colucci, M. Jenner, N. J. Oldham, J. Gomez, P. Reigan, Y. Li, C. I. De Matteis, D. Ross, and C. J. Moody, ChemBioChem, 2011, 12, 1203-1208.

4 Biologically active compounds: (a) A. Ichihara, M. Ubukata, H. Oikawa, K. Murakami, and S. Sakamura, Tetrahedron Lett., 1980, 21, 4469-4472 (b) H. Uno, J. Org. Chem., 1986, 51, 350-358; (c) M. A. Brimble, and S. M. Lynds, J. Chem. Soc., Perkin Trans. 1, 1994, 493-496. 
Pharmaceutical Compounds: (a) V. P. Papageorgiou, A. N Assimopoulou, E. A. Couladouros, D. Hepworth, and K. C. Nicolaou, Angew. Chem. Int. Ed., 1999, 38, 270; Angew. Chem. 1999, 111, 280; (b) E. A. Couladouros, and A. T. Strongilos, Eur. J. Org. Chem., 2002, 3341; (c) M. A. Brimble, M. R. Nairn, and H. Prabaharan, Tetrahedron, 2000, 56, 1937.

C-O coupling of alcohols: (a) S. Gowrisankar, A. G. Sergeev, P. Anbarasan, A. Spannenberg, H. Neumann, and M. Beller, J. Am. Chem. Soc. 2010, 132, 11592-11598; (b) Y. Zhu, K. Huang, J. Pan, X. Qiu, X. Luo, Q. Qin, J. Wei, X. Wen, L. Zhang, and N. Jiao, Nat. Commun., 2018, 9, 2625 ; (c) H. Zhang, P. Ruiz-Castillo, and S. L. Buchwald, Org. Lett., 2018, 20, 1580-1583; (d) S. Jana, Z. Yang, F. Li, C. Empel, J. Ho, and R. M. Koenigs, Angew. Chem. Int. Ed., 2020, 59, 5562-5566.

Csp3-H bond of alcohols: (a) C. He, S. Guo, L. Huang, and A. Lei, J. Am. Chem. Soc., 2010, 132(24), 8273-8275; (b) E. M. Simmons, and J. F. Hartwig, Nature, 2012, 483, 70 73; (c) J. M. Ketcham, I. Shin, T. P. Montgomery, and M. J. Krische, Angew. Chem. Int. Ed., 2014, 53, 9142-9150; (d) X. Wu, and C. Zhu, Chem. Commun., 2019, 55, 9747-9756; (e) C.-Y. Huang, J. Li, W. Liu, and C.-J. Li, Chem. Sci., 2019, 10, 5018-5024.

Coupling of Csp2-H and Csp3-H: (a) Z. Li, and C.-J. Li, J. Am. Chem. Soc. 2005, 127, 3672-3673; (b) Z. Li, L. Cao, and C.-J. Li, Angew. Chem. Int. Ed., 2007, 46, 6505-6507; (c) V. Rathore, M. Sattar, R. Kumar, and S. Kumar, J. Org. Chem., 2016, 81, 19, 9206-9218; (d) H. Zeng, J. Yu, and C.J. Li, Chem. Commun., 2020, 56, 1239-1242; (e) R. A. Thorat, S. Jain, M. Sattar, P. Yadav, Y. Mandhar, and S. Kumar, J. Org. Chem., 2020, 85, 14866-14878.
Light induced reaction: (b) K. Walsh, H. F. Sneddon, and C. J. Moody, Org. Lett., 2014, 16, 5224-5227; (c) H. Yi, C. Bian, X. Hu, L. Niua, and A. Lei, Chem. Commun., 2015, 51, 14046-14049; (d) S. Mitra, M. Ghosh, S. Mishra, and A. Hajra, J. Org. Chem., 2015, 80, 8275-8281; (e) G. Zhang, L. Zhang, H. Yi, Y. Luo, X. Qi, C.-H. Tung, L.-Z Wu, and A. Lei, Chem. Commun., 2016, 52, 10407-10410; (f) H. Yi, L. Niu, S. Wang, T. Liu, A. K. Singh, and A. Lei, Org. Lett., 2017, 19, 122-125; (g) S. Jana, A. Verma, R. Kadu, and S. Kumar, Chem. Sci., 2017, 8, 6633; (h) L. Niu, H. Yi, S. Wang, T. Liu, J. Liu, and A. Lei, Nat. Commun., 2017, 8, 14226; (i) J. Schwarz, and B. König, Green Chem., 2018, 20, 323-361; (j) G. Kibriya, S. Mondal, and A. Hajra, Org. Lett., 2018, 20, 7740-7743; (k) L. Niu, J. Liu, X.-A. Liang,
S. Wang, and A. Lei, Nat. Commun., 2019, 10, 467; (1) M. Singsardar, S. Mondal, S. Laru, and A. Hajra, Org. Lett., 2019, 21, 5606-5610.

10 Light induced C-C coupling: (a) M. Neumann, S. Füldner, B. König, and K. Zeitler, Angew. Chem. Int. Ed., 2011, 50, 951-954; (b) D. P. Hari, and B. König, Org. Lett., 2011, 13(15), 3852-3855; D. P. Hari, and B. König, Angew. Chem. Int. Ed., 2013, 52, 4734-4743; (c) D. P. Hari, P Schroll, and B. König, J. Am. Chem. Soc., 2012, 134, 2958-2961; (d) I. Ghosh, T. Ghosh, J. I. Bardagi, and B. König, Science, 2014, 346, 725-729; (e) Q.-Y. Meng, T. E. Schirmer, A. L. Berger, K. Donabauer, and B. König, J. Am. Chem. Soc., 2019, 141, 11393-11397; (f) V. Rathore, and S. Kumar, Green Chem., 2019, 21, 2670-2676; (g) Z. Qiu, D. M. Pham, J. Li, C.-C. Li, D. J. Castillo-Pazos, R. Z. Khaliullin, and C.-J. Li, Chem. Sci., 2019, 10, 10937-10943; (h) M. Liu, L. Tan, R. T. Rashid, Y. Cen, S. Cheng, G. Botton, Z. Mi, and C.-J. Li, Chem. Sci., 2020, 11, 7864-7870; (i) N. Ishida, Y. Kamae, Y. Ishizu, K.; Kamino, H. Naruse, and M. Murakami, J. Am. Chem. Soc., 2021, 143, 2217-2220.

11 Photo-acylation of naphthoquinone: (a) G. A. Kraus, and M. Kirihara, J. Org. Chem., 1992, 57, 3256; (b) G. A. Kraus, and P. Liu, Tetrahedron Lett., 1994, 35, 7723; (c) C. Schiel, M. Oelgemöller, and J. Mattay, Synthesis, 2001, 12751279; (d) C. Schiel, M. Oelgemöller, J. Ortner, and J. Mattay, Green Chem., 2001, 3, 224-228; (d) P. A. Waske, J. Mattay, and M. Oelgemöller, Tetrahedron Lett., 2006, 47, 1329-1332; (e) F. Friedrichs, B. Murphy, D. Nayrat, T. Ahner, M. Funke, M. Ryan, J. Lex, J. Mattay, and M. Oelgemöller, Synlett, 2008, 20, 3137-3140; (f) B. Murphy, P. Goodrich, C. Hardacre, and M. Oelgemöller, Green Chem., 2009, 11, 1867-1870; (g) L. J. Mitchell, W. Lewis, and C. J. Moody, Green Chem., 2013, 15, 2830; (h) F. D. Leon, S. Kalagara, A. A. Navarro, and S. Mito, Tetrahedron Lett., 2013, 54, 3147-3149.

12 A. Upadhyay, R. K. Jha, M. Batabyal, T. Dutta, A. L. Koner, and S. Kumar, Dalton Trans., 2021, 50, 14576-14594.

13 S. Shaaban, A. Negm, M. A. Sobh, and L. A. Wessjohann, Anti-Cancer Agents Med. Chem., 2016, 16, 621-632.

14 (a) J. M. Bruce, Q. Rev. Chem. Soc., 1967, 21, 405-428; (b) T. Mukherjee, PINSA, 2000, 66A (2), 248; (c) S. J. Blanksby, and G. B. Ellison, Acc. Chem. Res., 2003, 36, 255-263; (d) Y. Wang, S. Zhu, and L.-H. Zou, Eur. J. Org. Chem. 2019, 2179-2185. 